\title{
ARTICLE
}

Clinical Research

\section{Water vapor thermal therapy to alleviate catheter-dependent urinary retention secondary to benign prostatic hyperplasia}

\author{
Kevin T. McVary ${ }^{1}$ Bradley Holland ${ }^{2} \cdot$ J. Randolf Beahrs ${ }^{3}$
}

Received: 15 August 2019 / Revised: 29 October 2019 / Accepted: 4 November 2019 / Published online: 18 November 2019

(c) The Author(s) 2019. This article is published with open access

\begin{abstract}
Background Water vapor thermal therapy utilizes convectively delivered thermal energy to target ablation of obstructive prostatic tissue. We report results of this thermal therapy for relief of nonneurogenic complete urinary retention associated with BPH.

Patients and methods We conducted a retrospective analysis of 38 catheter-dependent men with complete urinary retention consecutively enrolled in a registry in two centers: median age 75.5 years and multiple comorbidities, median prostate volume $58.5 \mathrm{cc}$ (23-153), median 2 failed trials without catheter (TWOCs), and median catheter dependency 3 months (0.3-35). The Rezūm ${ }^{\mathrm{TM}}$ System thermal therapy procedure was performed in an ambulatory surgery center with conscious sedation or an office procedure room with a modified periprostatic block. Water vapor injections were customized to the configuration of the hyperplastic gland, including median lobe and/or enlarged central zone.

Results Of the 38 treated patients, one was lost to follow-up and 26 of 37 (70.3\%) voided spontaneously (mean of $1.6 \pm 0.8$ TWOCs) and were catheter free a median of 26 days (range 4-65) after the procedure; 18 of these 26 (69\%) patients discontinued BPH medications. No significant differences in age, prostate volume, number of water vapor injections, or presence of the median lobe were associated with predicting a successful treatment outcome. Duration of follow-up for 20 catheter-free patients was a median of 475 days or 15.8 months (140-804 days); six patients were followed a median of 31.5 days (0-60). Adverse events were infrequent, mild, and resolved quickly including dysuria in five patients (13\%), gross hematuria in four $(10.5 \%)$, and UTIs in two $(2.6 \%)$ with indwelling catheters.

Conclusions Water vapor thermal therapy may provide an effective and safe alternative to surgical treatment in this group of catheter-dependent patients in complete urinary retention.
\end{abstract}

\section{Introduction}

Water vapor thermal therapy with the Rezūm ${ }^{\mathrm{TM}}$ System utilizes convectively delivered thermal energy to target ablation of obstructive prostatic tissue. This minimally invasive surgical treatment now has a substantial history as an efficient, effective, and safe modality to treat clinically significant BPH [1-4]. The procedure is currently

Kevin T. McVary

kmcvary@gmail.com

1 Department of Urology, Stritch School of Medicine, Loyola University Medical Center, Maywood, IL, USA

2 Division of Urology, Southern Illinois University School of Medicine, Springfield, IL, USA

3 Minnesota Urology, Woodbury, MN, USA recommended for ablation of lateral and median lobes of the prostate [5]. It may be performed in an outpatient or office-based setting without general anesthesia and provides durable relief of LUTS. It may be offered to patients as firstline treatment for moderate-to-severe LUTS due to BPH and appears to lower the rate of clinical progression of BPH while preserving sexual function compared with daily longterm use of pharmaceutical agents [6]. This thermal therapy can be considered as an alternative before or after pharmacotherapy, for patients reluctant to undergo a traditional surgical procedure, and for those at high anesthesia risk due to poor health and comorbidities.

Urinary retention is a major risk factor associated with $\mathrm{BPH}$, which is in part responsible for domains of LUTS including hesitancy, intermittency, poor flow, and large PVRs. The natural history of LUTS/BPH may culminate in urinary retention, an adverse event men rank as significant as myocardial infarction or cerebral vascular accident [7]. 
Catheter-dependent patients seek treatment to improve bladder function and quality of life, particularly to reduce long-term catheter complications. Operative procedures to relieve bladder outlet obstruction from BPH in older or frail patients with high comorbidities are fraught with potential complications including anesthesia risk, UTI with septicemia, surgical bleeding, urethral stricture, and possible incontinence [8].

The aim of this report is to share our experience with water vapor thermal therapy for treatment of medically refractory, complete urinary retention to achieve successful cessation of catheter dependency in older patients, most considered unsuitable for traditional bladder outlet surgery.

\section{Patients and methods}

\section{Study procedures}

Patients were consecutively evaluated at two urology centers, a university clinic, and a private urology practice, and compiled into a single retrospective registry-Rezūm Retention Registry. Accrual was typically by referral after initial presentation in an emergency department (13), by a primary care physician or urologist (12), or established and new patients in the private practice (13). Once accrued, patients were evaluated with history, physical examination, and transrectal ultrasound prostate volume. They were treated one time with the water vapor thermal therapy procedure. To avoid confusion with urinary retention terminology specifically for these patients who had variable durations of retention, they were classified as being in complete urinary retention. The primary objective of the water vapor thermal therapy procedure was to achieve patients being able to void without further intervention and be relieved of catheter dependence. A secondary objective was discontinuance of $\mathrm{BPH}$ medications. Institutional review board approval was obtained; patient confidentiality was strictly maintained for the retrospective review.

\section{Thermal therapy procedure}

Convective radiofrequency water vapor thermal therapy with the Rezūm ${ }^{\mathrm{TM}}$ System (Boston Scientific Corporation, Marlborough, MA) utilizes transurethral endoscopic guidance. The intent of the procedure is to create continuous, overlapping ablative lesions running parallel to the natural slope of the prostatic urethra, eliminating tissue interfering with natural function. The technology, device, and procedure have been previously described in detail $[1,3,9]$. Briefly, contours of the prostate and planned disbursement of thermal lesions are determined at cystoscopy. The total number of vapor treatments in each prostate lobe is determined by length of the prostatic urethra and can be customized to the configuration of the hyperplastic gland, which may include median lobe or enlarged central zone. For patients who undergo a Rezūm procedure, an indwelling catheter may be left in place for several days to allow for reduction in edema associated with ablated tissue and to avoid irritative symptoms when the patient is able to void spontaneously. The expectations and guidance for postoperative management after the thermal therapy procedure have been reported [9].

\section{Statistical methods}

Descriptive statistics were used to describe baseline and follow-up values for all variables. Data are presented as the mean $\pm \mathrm{SD}$ or median. As the response groups were small and unequal in size the two-sample Wilcoxon test was used to assess whether there were differences between those who achieved catheter independence after treatment and those who did not. $P<0.05$ was considered statistically significant.

\section{Results}

This Rezūm Retention Registry retrospective analysis included 38 patients in urinary retention associated with BPH and dependent on either an indwelling catheter or clean intermittent self-catheterization (CIC). These patients were unable to empty their bladder in any sufficient way. Most patients were in poor health or unsuitable for surgery owing to existing cardiovascular, pulmonary, gastroenterological, neurological, or other diseases and for whom a surgical alternative was needed (Table 1). The university center described 13 of 18 (72\%) patients as high-risk chronic urinary retention (CUR) due to concomitant hydronephrosis, recurrent UTIs, urosepsis, $\geq$ stage 3 chronic renal disease, or glomerular filtration rate $<60 \mathrm{~mL} / \mathrm{min}$. This risk assessment for CUR was not documented at the private urology practice. Patient median age was 75.5 years (range 59-90); median prostate volume was $58.5 \mathrm{cc}$ (range 23-153).

Some patients were without comprehensive baseline information such as duration of LUTS/BPH, number of failed TWOCs, and assessment of bladder function; urodynamic studies were either not performed or results were not accessible. Although all patients had LUTS/BPH, a temporal history was documented in only 18 of 38 with a median duration of 3.5 years (range $>1-15$ ). Catheter dependency before the thermal therapy procedure was a median of 3 months (range 0.3-35). Some patients had either long-term Foley catheter drainage or long-term CIC. 
Table 1 Baseline characteristics and outcomes after water vapor thermal therapy

\begin{tabular}{|c|c|c|c|c|}
\hline & $\begin{array}{l}\text { All patients* } \\
N=38\end{array}$ & $\begin{array}{l}\text { Catheter free } \\
N=26\end{array}$ & $\begin{array}{l}\text { Catheter dependent } \\
N=11\end{array}$ & $P^{*}$ \\
\hline \multicolumn{5}{|l|}{ Baseline characteristics } \\
\hline Age, years, mean & $76.0 \pm 9.1$ & $75.0(9.7)$ & $79.2(7.2)$ & 0.33 \\
\hline Median [range] & $75.5(59-90)$ & $75[59-89]$ & $76[70-90]$ & \\
\hline Prostate size, $\mathrm{cm}^{3}$ & $64.4 \pm 35.4$ & $62.3(32.2)$ & $72.1(45.4)$ & 0.77 \\
\hline Median [range] & $58.5(23-153)$ & $52[23-137]$ & $61[25-153]$ & \\
\hline Prior bladder function assessment & 4 & 3 & 1 & \\
\hline Using anticoagulant medications & 9 & 5 & 4 & \\
\hline \multicolumn{5}{|l|}{ ASA physical status classification } \\
\hline ASA II & 4 of 18 & 3 & 1 & \\
\hline ASA III & 7 of 18 & 4 & 3 & \\
\hline ASA IV & 7 of 18 & 6 & 1 & \\
\hline ASA not assessed & 20 & 13 & 6 & \\
\hline \multicolumn{5}{|l|}{ Comorbidities reported $^{\dagger}$ (no. of patients) } \\
\hline Cardiovascular & $39(24)$ & $29(17)$ & $10(7)$ & \\
\hline Gastrointestinal & $20(18)$ & $18(16)$ & $2(2)$ & \\
\hline Genitourinary & $13(11)$ & $11(9)$ & $2(2)$ & \\
\hline Endocrinological & $13(11)$ & $10(9)$ & $3(2)$ & \\
\hline Oncological & $12(8)$ & $11(7)$ & $1(1)$ & \\
\hline Neurological & $10(6)$ & $6(4)$ & $4(2)$ & \\
\hline Nephrological & $5(5)$ & $2(2)$ & $3(3)$ & \\
\hline Pulmonary & $3(3)$ & $3(3)$ & $0(0)$ & \\
\hline Duration of catheter dependence & $4.5 \pm 6.5$ & $3.1(2.1)$ & $7.9(11.2)$ & 0.60 \\
\hline Months, Median [range] & $2.5(0.5-35)$ & $2[<1-8]$ & $4[<0.5-35]$ & \\
\hline No. of previous failed TWOC & & & $>2$ & 0.18 \\
\hline Median [range] & $2[0-4]$ & $2.5[1-4]$ & (Many on CIC) & \\
\hline \multicolumn{5}{|l|}{ Treatment and outcomes } \\
\hline \multicolumn{5}{|l|}{ No. of water vapor injections, mean [range] } \\
\hline Total all zones treated & - & $5.7[2-10]$ & $5.4[2-10]$ & \\
\hline Right and left lobe & - & $4.6[2-9]$ & $4.1[2-8]$ & \\
\hline Median lobe & - & $1.1[0-3]$ & $1.3[0-2]$ & \\
\hline $\begin{array}{l}\text { No. with median lobe identified and treated } \\
(\%)\end{array}$ & - & 19 of $25(76.0 \%)$ & 9 of $11(81.8 \%)$ & 1.00 \\
\hline Catheter type post procedure until TWOC, $(n)$ & - & IDC (12) CIC (14) & IDC (6) CIC (5) & \\
\hline Time to successful TWOC, days & - & $26.6(14.1)$ & - & \\
\hline Median [range] & & $26[4-65]$ & & \\
\hline Discontinued BPH medications, $n(\%)$ & - & & & \\
\hline Yes & & $18 / 26(69.2 \%)$ & - & \\
\hline No & & $5 / 26(19.2 \%)$ & - & \\
\hline Tapering until lost to follow up & & $1 / 26(3.8 \%)$ & - & \\
\hline Never used medications & & $2 / 26(7.7 \%)$ & - & \\
\hline \multicolumn{5}{|c|}{ Duration of follow-up for catheter-free patients ( $n$ ) median, days, months [range] } \\
\hline$\leq 60$ days $(6)$ & & $\begin{array}{l}31.5 \text { days } \\
{[14-60 \text { days }]}\end{array}$ & - & \\
\hline \multirow[t]{2}{*}{$>61$ days $(20)$} & & $\begin{array}{l}475 \text { days or } \\
15.8 \text { months }\end{array}$ & - & \\
\hline & & [140-804 days] & & \\
\hline
\end{tabular}

*One patient lost to follow up for outcome assessment

${ }^{\dagger}$ Some patients had 2-4 comorbidities in one or more systems

For those patients (25 of 38) with information on number of TWOCs, the median was two failed TWOCs. Not all patients had a PVR in our record for various reasons, namely, sometimes the referral sources did not have means to measure PVR prior to insertion of catheter or patients had multiple failed TWOCs each with a variable PVR prior to reinsertion of the Foley catheter. There was no set protocol to declare the cardinal PVR. For 21 of 38 (55\%) patients with a reported baseline PVR, median was $320 \mathrm{~mL}$ (range 100-2500).

All thermal therapy procedures were successfully performed in an ambulatory surgery center or office 
procedure room and completed without perioperative device or procedure-related AEs. A total of 14 of 18 (78\%) university center patients were characterized as ASA class III or IV. These patients received conscious sedation during the thermal therapy procedure. The private practice performed a modified periprostatic block for anesthesia in all procedures as described previously [9]. After the thermal therapy procedure either an indwelling catheter was inserted or CIC was taught to the patient, depending on the patient's willingness, ability to comply, and physical health. A TWOC was generally performed at 1 week and then weekly thereafter. This was done by a trial of "fill and void" checking the PVR thereafter once or 1-2 times weekly for 1 month, then at 3 months and 6 months.

Eighteen patients had an indwelling catheter and 19 patients performed CIC after the thermal therapy procedure before the voiding trials (Table 1). Twenty-six of the 37 evaluable treated patients were able to spontaneously void after the procedure for an overall success rate of $70.3 \%$ (Table 1). Only one patient was lost to follow-up immediately after treatment and remained catheter dependent at that time. Both clinical centers reported similar success rates, notably 13 of $18(72.2 \%)$ and 13 of $20(65 \%)$. Patients voiding spontaneously had a mean of $1.6 \pm 0.8$ TWOCs and were catheter free a median of 26 days (range 4-65) after thermal therapy. A total of 18 of $26(69.2 \%)$ catheter-free patients were able to discontinue their oral BPH medications. While the factors for a successful or failed outcome could not be definitively determined, they did not appear to be related to any significant differences in age $(p=0.33)$, prostate volume $(p=0.77)$, or number of water vapor injections, or presence of the median lobe. The percentage of men with large prostates $\geq 80 \mathrm{cc}$ was greater in those with TWOC successes ( 7 of 26 , $28.0 \%$; volume range $81-153 \mathrm{cc}$ ) versus TWOC failures ( 2 of 11, 22.2\%; volume range 91-129 cc). The duration of time patients were catheter dependent before treatment, a median of 3 months (range 10 days to 35 months) was markedly variable. Duration of follow-up for 20 of 26 catheter-free patients was a median of 475 days or 15.8 months (range 140-804 days) and a relatively brief follow-up duration for six patients was a median of 31.5 days (range $0-60$ ). With the exception of one patient who required catheter use almost 2 years after the thermal therapy procedure, the others were catheter independent at the last documented visit.

Nonserious anticipated adverse events that may develop after a rigid cystoscopic procedure were infrequent, of short duration and mild in severity. These events included dysuria in five patients $(13 \%)$, gross hematuria in four patients $(10.5 \%)$, and UTIs in two patients with an indwelling catheter post treatment $(2.6 \%)$.

\section{Discussion}

The current urologic state of the art management of BPH is evolving on a reasonably rapid scale. Minimally invasive procedures, easily administered in the office, appear to eclipse the need for aggressive pharmacologic management in most cases and avoid the cost and adverse effects of the drug therapy. Some BPH patients progress to a point of complete urinary retention either by significant prostate growth, underactive bladder contractility, or combination of both. This urinary retention is often the tipping point requiring surgical therapy with aggressive removal of obstructing tissue. Our observational study of several such patients demonstrates the advantages and acceptable outcomes of water vapor thermal therapy to reduce $\mathrm{BPH}$ burden.

Urinary retention remains a common indication for a TURP. Patients who present in retention due to high failure rates of medical management are typically offered TURP to free them from long-term catheter use. The success rate of TURP appears to be significantly affected by age. In one report of 95 men with mean follow-up of 704 days, $87.4 \%$ were catheter free either at the time of follow-up or prior to death. The mean age of catheter-free men was 74.3 years compared with 84.9 years for men who remained catheter dependent [10]. Patients operated on after complete urinary retention have an increased mortality rate, unrelated to retention, but reflecting the advanced stage of BPH usually seen in elderly patients presenting with multiple medical conditions.

The incidence and prevalence of CUR is unknown. However, publications from the United Kingdom have reported the incidence of CUR in men who underwent TURP ranging from 14 to $37 \%$ [11-13]. Due to the increased operative risk of TURP, as well as AEs for these patients, nonsurgical treatment alternatives are required to meet their needs. Studies in the early 2000s and after reported the first successes with TUMT for urinary retention with TWOC success rates ranging from 72 to $82 \%$ [14-19]. In a later randomized, controlled trial of catheter-dependent patients treated with TUMT or TURP/enucleation at 6 months of follow-up 79 and $88 \%$ of men were catheter free, respectively [18]. A high rate of UTIs occurred with both treatments, $33 \%$ for TUMT and $22 \%$ for TURP, however with a significantly greater number of serious AEs of $8.5 \%$ with TURP versus $1.6 \%$ for TUMT. A lower frequency of AEs for TUMT, $2 \%$ versus $17 \%$ for TURP, was also reported in patients with clinical BPH although without retention [20]. When comparing rates of restored spontaneous voiding in patients treated with TUMT and Rezūm, Rezūm patients in this study were older, their prostate volumes were greater, a higher percentage was identified as unsuitable for traditional surgery, and additionally there was 
a high rate of postoperative BPH medication cessation, an observation not reported in other studies. The convective water vapor thermotherapy in comparison to conductive TUMT ablation may represent a more efficient modality, which affords the ability to safely treat a hyperplastic central zone and median lobe.

There was great variability in pretreatment PVR and duration of catheter dependence for our study patients with recalcitrant urinary retention. Some men did not meet the consensus definition of nonneurogenic CUR supported by the AUA and International Continence Society [21, 22]. That is, CUR defined as an elevated PVR of $\geq 300 \mathrm{~mL}$ that persisted for at least 6 months and documented on two or more separate occasions. The evidence for this definition is considered expert opinion only as few urologists would recommend a 6 month delay before attempting an effective treatment for retention just to meet the time component therein $[21,23]$. Clearly there is little standardization in the duration or PVR necessary for diagnosis and treatment of CUR. Research studies often use a PVR $>300 \mathrm{~mL}$ to diagnose CUR; others have used 100, 400, and $500 \mathrm{~mL}$ [24]. In addition, urinary retention is produced from variable pathogenic mechanisms that create neurologic detrusor underactivity and/or chronic bladder outlet obstruction. Definitions aside, patients assessed herein may be typical of those with catheter-dependent retention presenting in community primary or urology practices or referred to tertiary university centers, many without previous or inconsistent medical care for their BPH and without prior full work-ups. The management of their condition must transcend definition and provide timely relief.

Although the study sample size is small the similar success rates between the two centers support the generalizability of the water vapor thermal therapy procedure in treating this recalcitrant high-risk group presenting with complete retention. Despite the solace found in $~ 70.3 \%$ TWOC success rate in effectively treating this population, we agree that further study using an active comparator group (i.e., water vapor thermal therapy versus TURP) and a standardized urodynamic assessment is needed. How to interpret the observation that successful TWOC was noted in those with larger prostates seems counterintuitive. One possibility is that the larger prostate cohort may represent those with more obstruction-linked retention rather than detrusor underactivity related retention. Without baseline urodynamics this putative dichotomy remains conjecture.

A limitation of this registry study includes the absence of thorough baseline assessments in some patients that would assist evaluation of comparative changes in urinary symptom scores and quality of life measures (i.e., I-PSS). In addition, in men whose retention has lasted many months prior to effective thermal therapy treatment, the validity of a recalled I-PSS score is known to be inaccurate muting the impact of a lack of baseline I-PSS in this cohort [25]. While these baseline evaluations are expected in a clinical trial, our observations with limited data may represent the reality in the clinical setting. This report lacks a uniform approach to the withdrawal of BPH/LUTS medications, but there is ample evidence herein that this is frequently possible.

Our reported results, outside the realm of a formal clinical study, support a nonsurgical and efficient therapeutic option with water vapor thermal therapy for patients presenting with catheter-dependent urinary retention. For elderly patients or those in poor physical health considered at high risk for intraoperative complications and postoperative morbidity, this study shows that for many of these patients water vapor thermal therapy could contribute considerably providing relief of their catheter and BPH medications and improving quality of life. Longer term follow-up to determine duration of catheter independence will be essential to evaluate merits of the Rezūm procedure.

\section{Conclusions}

Water vapor thermal therapy was effective to restore successful spontaneous voiding in a majority of patients with obstructive BPH necessitating a urethral catheter for complete urinary retention. The water vapor thermal therapy represents a new technological approach for ablation of obstructive benign prostate adenomas. As a minimally invasive surgical procedure it represents an alternative for treatment of catheter-dependent urinary retention in elderly and frail patients who are at anesthesia risk for invasive surgical approaches to relieve retention.

Acknowledgements The authors wish to thank Danuta Dynda, MD, and Ahmed El-Zawahry, MD, Division of Urology, Southern Illinois University and Diane L. Kachel, Minnesota Urology for assistance with the study. Editorial/medical writing support under the guidance of the authors was provided by Elaine K. Orenberg, Ph.D., Stanford, CA.

\section{Compliance with ethical standards}

Conflict of interest KTM served as clinical study investigators on the pivotal trial of the water vapor thermal therapy (Rezūm System) sponsored by NxThera, Inc. (acquired by Boston Scientific) and has consulted for Boston Scientific and received compensation. JRB served as a clinical study investigator on the pivotal trial of water vapor thermal therapy sponsored by NxThera, Inc. BH declares no potential conflict of interest. The authors received no commercial funding or personal compensation for conduct of the Rezūm Registry Study.

Publisher's note Springer Nature remains neutral with regard to jurisdictional claims in published maps and institutional affiliations. 
Open Access This article is licensed under a Creative Commons Attribution 4.0 International License, which permits use, sharing, adaptation, distribution and reproduction in any medium or format, as long as you give appropriate credit to the original author(s) and the source, provide a link to the Creative Commons license, and indicate if changes were made. The images or other third party material in this article are included in the article's Creative Commons license, unless indicated otherwise in a credit line to the material. If material is not included in the article's Creative Commons license and your intended use is not permitted by statutory regulation or exceeds the permitted use, you will need to obtain permission directly from the copyright holder. To view a copy of this license, visit http://creativecommons. org/licenses/by/4.0/.

\section{References}

1. McVary KT, Gange SN, Gittelman MC, Goldberg KA, Patel K, Shore ND, et al. Minimally invasive prostate convective water vapor energy (WAVE) ablation: a multicenter, randomized, controlled study for treatment of lower urinary tract symptoms secondary to benign prostatic hyperplasia. J Urol. 2016;195:1529-39.

2. Woo HH, Gonzalez RR. Perspective on the Rezūm System: a minimally invasive treatment strategy for benign prostatic hyperplasia using convective radiofrequency water vapor thermal therapy. Med Dev. 2017;10:71-80.

3. Darson MF, Alexander EE, Schiffman ZJ, Lewitton M, Light RA, Sutton MA, et al. Procedural techniques and multicenter postmarket experience using minimally invasive convective radiofrequency thermal therapy with Rezūm System for treatment of lower urinary tract symptoms due to benign prostatic hyperplasia. Res Rep Urol. 2017;9:159-68.

4. McVary KT, Rogers T, Roehrborn CG. Rezūm water vapor thermal therapy for lower urinary tract symptoms associated with benign prostatic hyperplasia: 4-year results from randomized controlled study. Urology. 2019;126:171-9.

5. Foster HE, Barry MJ, Dahm P, Gandhi MC, Kaplan SA, Kohler TS, et al. Surgical management of lower urinary tract symptoms attributed to benign prostatic hyperplasia: AUA guideline. J Urol. 2018;200:612-9.

6. Gupta N, Rogers T, Holland B, Helo S, Dynda D, McVary KT. Three-year treatment outcomes of water vapor thermal therapy (Rezūm System) compared to doxazosin, finasteride and combination drug therapy for men with benign prostatic hyperplasia: cohort data from the Medical Therapy of Prostatic Symptoms (MTOPS) Trial. J Urol. 2018;200:405-13.

7. Kawakami J, Nickel JC. Acute urinary retention and surgery for benign prostatic hyperplasia: the patient's perspective. Can J Urol. 1999;6:819-22

8. Brasure M, Fink HA, Risk M, MacDonald R, Shamliyan T, Ouellette J, et al. Chronic urinary retention: comparative effectiveness and harms of treatments. comparative effectiveness review no. 140. (Prepared by the Minnesota Evidence-based Practice Center under Contract No. 290-2007-10064-I.) AHRQ publication no. 14-EHC041-EF. Rockville, MD: Agency for Healthcare Research and Quality; 2014. www.effectivehealthcare. ahrq.gov/reports/final.cfm.

9. Cantrill CH, Zorn KC, Elterman DS, Gonzalez RR. The Rezūm system - a minimally invasive water vapor thermal therapy for obstructive benign prostatic hyperplasia. Can J Urol. 2019;26: 9787-93.

10. Losco G, Mark S, Jowitt S. Transurethral prostate resection for urinary retention: does age affect outcome? ANZ J Surg. 2013; 83:243-5.

11. Gujral S, Abrams P, Donovan JL, Neal DE, Brookes ST, Chacko $\mathrm{KN}$, et al. A prospective randomized trial comparing transurethral resection of the prostate and laser therapy in men with chronic urinary retention: the CLasP study. J Urol. 2000;164:59-64.

12. Emberton M, Neal DE, Black N, Harrison M, Fordhams M, McBrien MP, et al. The National Prostatectomy Audit: the clinical management of patients during hospital admission. Br J Urol. 1995;75:301-16.

13. Doll HA, Black A, McPherson K, Williams GB, Smith JC. Differences in outcome of transurethral resection of the prostate for benign prostatic hypertrophy between three diagnostic categories. Br J Urol. 1993;72:322-30.

14. Djavan B, Wammack R, Ghawidel K, Alavi S, Hasenzagel C, Dobronski $\mathrm{P}$, et al. Microwave thermotherapy in patients with chronic urinary retention. Tech Urol. 2000;6:278-81.

15. Naqvi SA, Rizvi SA, Hasan AS. High-energy microwave thermotherapy in patients in urinary retention. J Endourol. 2000;14:677-81.

16. Schelin S. Microwave thermotherapy in patients with benign prostatic hyperplasia and chronic urinary retention. Eur Urol. 2001;39:400-4.

17. Kellner DS, Armenakas NA, Brodherson M, Heyman J, Fracchia JA. Efficacy of high-energy transurethral microwave thermotherapy in alleviating medically refractory urinary retention due to benign prostatic hyperplasia. Urology. 2004;64:703-6.

18. Schelin S, Geertsen U, Walter S, Spånberg A, Duelund-Jacobsen J, Krøyer K, et al. Feedback microwave thermotherapy versus TURP/ prostate enucleation surgery in patients with benign prostatic hyperplasia and chronic urinary retention: a prospective, randomized, controlled, multicenter study. Urology. 2006;68:795-9.

19. Aagaard MF, Niebuhr MH, Jacobsen JD, Krøyer Nielsen K, et al. Transurethral microwave thermotherapy treatment of chronic urinary retention in patients unsuitable for surgery. Scand J Urol. 2014;48:290-4.

20. Wagrell L, Schelin S, Nordling J, Richtoff J, Magnusson B, Schain M, et al. Three-year follow-up of feedback microwave thermotherapy versus TURP for clinical BPH: a prospective randomized multicenter study. Urology. 2004;64:699-702.

21. Stoffel JT, Peterson AC, Sandhu JS, Suskind AM, Wei JT, Lightner DJ. AUA white paper on nonneurogenic chronic urinary retention: Consensus definition, treatment algorithm, and outcome end points. J Urol. 2017;198:153-60.

22. D'Ancona C, Haylen B, Oelke M, Abranches-Monteiro L, Arnold E, Goldman H, et al. The International Continence Society (ICS) report on the terminology for adult male lower urinary tract and pelvic floor symptoms and dysfunction. Neurourol Urodyn. 2019;38:433-77.

23. Negro CLA, Muir GH. Chronic urinary retention in men: how we define it, and how does it affect treatment outcome. BJU Int. 2012;110:1590-4.

24. Kaplan SA, Wein AJ, Staskin DR, Roehrborn CG, Steers WD. Urinary retention and post-void residual urine in men: separating truth from tradition. J Urol. 2008;180:47-54.

25. Helfand BT, Fought A, Manvar AM, McVary KT. Determining the utility of recalled lower urinary tract symptoms. Urology. 2010;76:442-7. 